\title{
Experimental Study on Sisal Fibre Reinforced concrete With Partial Replacement of Cement by Ground Granulated Blast furnace Slag
}

\author{
P. Sathish ${ }^{1}$, V. Murugesh ${ }^{2}$ \\ ${ }^{1}$ Student (M.E. Structural Engineering), JCT College of Engineering and Technology Pichanur Coimbatore \\ ${ }^{2}$ Assistant professor of Civil Engineering, JCT College of Engineering and Technology Pichanur Coimbatore
}

\begin{abstract}
The study focuses on the compressive strength, split tensile strength, flexural strength performance of the blended concrete containing sisal fibre and different percentage of slag as a partial replacement of OPC. The cement in concrete is replaced accordingly with the percentage of $10 \%, 20 \%$ and $30 \%$ by weight of slag and $1 \%$ of sisal fibre is added by weight of cement. Concrete cubes are tested at the age of 7, 14, and 28 days of curing. Finally, the strength performance of slag blended fibre reinforced concrete is compared with the performance of conventional concrete. From the experimental investigations, it has been observed that, the optimum replacement of Ground Granulated Blast Furnace Slag Powder to cement is $20 \%$ for M30 grade
\end{abstract}

Keywords: Sisal fibre, ground granulated blast furnace slag,compressive strength, split tensile strength, flexural strength

\section{Introduction}

The manufacture of concrete, primarily its ingredients; cement and aggregates; presents various sustainability issues that need to be dealt. The production of concrete has always lead to massive exploitation of natural resources. Manufacturing 1 tonne of Portland cement requires quarrying 1.5 tonnes of limestone and clay (Civil and Marine, 2007). Moreover, continuous extraction of natural aggregate; sand and gravel; from river beds, lake and other water bodies over the years have led to erosion which eventually leads to flooding and landslides. Further, there is less filtration of rainwater due to reduced amount of natural sand, causing contamination of water needed for human consumption. 1.4 tonnes of Ordinary Portland cement being produced yearly around the globe contributes to 5 percent of greenhouse gas, carbon dioxide, emissions worldwide (Civil and Marine, 2007). Not only burning fuel to heat the kiln emits carbon dioxide, but also decomposition of limestone emits even more gas. These identified problems clearly, contribute significantly to climate change. The ideal target to partly solve the above phenomenon is to develop a sustainable system loop which can turn resources which are landfilled as waste materials into useful products in the construction industry, thus preserving the natural resources.

Concrete is a tension-weak building material, which is often crack ridden connected to plastic and hardened states, drying shrinkage, and the like. The cracks generally develop with time and stress to penetrate the concrete, thereby impairing the water proofing properties and exposing the interior of the concrete to the destructive substances containing moisture, bromine, acid sulphate, etc. The exposure acts to deteriorate the concrete, with the reinforcing steel corrosion. To counteract the cracks, a fighting strategy has come into use, which mixes the concrete with the addition of discrete fibres and pozzolanic materials. Experimental studies have shown that fibres and pozzolanic materials improve the mechanicalproperties of concrete such as flexural strength, compressive strength, tensile strength, creep behaviour, impact resistance and toughness. Moreover, the addition of fibres and pozzolanic materials makes the concrete more homogeneous and isotropic.

\section{Materials Used}

\section{Cement}

Ordinary Portland cement of Grade 53 has been used in the study. Table 1 shows the physical characteristics of cement used, tested in accordance with IS: 4031-1988.

Table 1: Physical properties of cement

\begin{tabular}{|c|c|c|}
\hline SI.NO & Specifications & Results \\
\hline 1 & Type & OPC \\
\hline 2 & Specific Gravity & 3.10 \\
\hline 3 & Initial setting time & 40 minutes \\
\hline 4 & Final setting time & 450 minuts \\
\hline 5 & Fineness & $2 \%$ \\
\hline
\end{tabular}

Fine aggregates

The fine aggregate used was locally available river sand without any organic impurities and conforming to IS: $383-$ 1970.The fine aggregate was tested for its physical requirements such as gradation, fineness modulus, specific gravity and bulk density and is shown in table 2 .

Table 2: Properties of fine aggregate

\begin{tabular}{|c|c|c|}
\hline SI.NO & Specifications & Results \\
\hline 1 & Type & River sand \\
\hline 2 & Specific gravity & 2.6 \\
\hline 3 & Grading & Zone III \\
\hline
\end{tabular}

\section{Coarse Aggregate}

The crushed coarse aggregate obtained from the local crushing plant is used in the present study.The physical properties of coarse aggregate like specific gravity, water absorption and fineness modulus are tested in accordance with IS: 2386 are given in Table3. 


\section{International Journal of Science and Research (IJSR) \\ ISSN (Online): 2319-7064}

Index Copernicus Value (2013): 6.14 | Impact Factor (2015): 6.391

Table 3: Properties of Coarse Aggregate

\begin{tabular}{|c|c|c|}
\hline SI.NO & Specifications & Results \\
\hline 1 & Fineness modulus & 8.26 \\
\hline 2 & Specific gravity & 2.82 \\
\hline 3 & Water absorption & 2.8 \\
\hline
\end{tabular}

\section{Water}

Water used for mixing and curing was potable water, which was free from any amounts of oils, acids, alkalis, sugar, salts and organic materials or other substances that may be deleterious to concrete or steel. The $\mathrm{pH}$ value should not be less than 6 .

\section{Sisal Fibre}

Sisal fibre is a species of Agava. It is botanically known as Agave sisalana. The material is chosen to improve the various strength properties of the structure to obtain sustainability and better quality structure. Short discrete vegetable fibre (sisal) was examined for its suitability for incorporation in cement concrete. The physical property of this fibre has shown no deterioration in a concrete medium. Leaves are dried, brushed and baled to form fibre.

\section{Properties of Sisal Fibre}

- Sisal Fibre is exceptionally durable with a low maintenance with minimal wear and tear.

- It is Recyclable.

- Sisal fibres are obtained from the outer leaf skin, removing the inner pulp.

- It is available as plaid, herringbone and twill.

- Sisal fibres are Anti-static, does not attracts or traps dust particles and do not absorb moisture or water easily.

- The fine texture takes dyes easily and offers the largest range of dyed colours of all natural fibres.

- It exhibits good sound and impact absorbing properties.

- Its leaves can be treated with natural borax for fire resistance properties.

Chemical Composition of Sisal Fibre

\begin{tabular}{|c|c|}
\hline Cellulose & $65 \%$ \\
\hline Hemicelluloses & $12 \%$ \\
\hline Lignin & $9.9 \%$ \\
\hline Waxes & $2 \%$ \\
\hline Total & $100 \%$ \\
\hline
\end{tabular}

Identification of Sisal Fibre

\begin{tabular}{|c|c|c|c|c|}
\hline $\begin{array}{c}\text { Name } \\
\text { of fibre }\end{array}$ & Fibre type & Flame reaction & Colour & $\begin{array}{c}\text { After Burn } \\
\text { order }\end{array}$ \\
\hline $\begin{array}{c}\text { Sisal } \\
\text { fibre }\end{array}$ & $\begin{array}{c}\text { May flair when } \\
\text { lit, burn }\end{array}$ & $\begin{array}{c}\text { Soft grey } \\
\text { ash }\end{array}$ & $\begin{array}{c}\text { Burning } \\
\text { paper or } \\
\text { grass }\end{array}$ \\
\hline
\end{tabular}

\section{Ground Granulated Blast furnace Slag}

GGBS, a by-product of iron manufacture, is a glassy, nonmetallic granular material which exhibits cementitious properties on its own while others do so in the presence of Portland cement and calcium sulphate which are activators. Thus, GGBS acts as pozzolans and is therefore combined with Portland cement; resulting in a hardened cement of GGBS combined with Portland cement, which has more of smaller gel pores and fewer larger capillary pores than that of normal Portland cement which consequently results in lower permeability and hence greater durability. Moreover, it contains less free lime, which in its presence forms ettringite or efflorescence, and makes the resulting hardened cement more chemically stable. In addition, GGBS has a lower content of $\mathrm{C} 3 \mathrm{~A}$ than normal cement, thus decreasing the reactivity with sulphate.

\section{Chemical Composition of GGBS}

GGBS has the same main chemical constituents as ordinary Portland cement, but in different proportion.

\begin{tabular}{|c|c|c|}
\hline Chemical Constituents & Portland & GGBS \\
\hline $\mathrm{CaO}$ & $65 \%$ & $40 \%$ \\
\hline $\mathrm{SiO}_{2}$ & $20 \%$ & $35 \%$ \\
\hline $\mathrm{Al}_{2} \mathrm{O}_{3}$ & $5 \%$ & $10 \%$ \\
\hline $\mathrm{MgO}$ & $2 \%$ & $8 \%$ \\
\hline
\end{tabular}

Physical Properties of GGBS

\begin{tabular}{|c|c|}
\hline Colour & Off-white powder \\
\hline Bulk density (loose) & $1.0-1.1$ tonnes $/ \mathrm{m}^{3}$ \\
\hline Bulk density (vibrated) & $1.2-1.3$ tonnes $/ \mathrm{m}^{3}$ \\
\hline Relative density & $2.85-2.95$ \\
\hline Surface area & $400-600 \mathrm{~m}^{2} / \mathrm{kg}$ Bline \\
\hline
\end{tabular}

\section{Super Plasticizer}

A substance which imparts very high workability with a large decrease in water content (at least 20\%) for a given workability. A high range water reducing admixture (HRWRA) is also referred as Super plasticizer, which is capable of reducing water content by about 20 to 40 percent has been developed. The effect of Super plasticizers lasts only for 30to 60 minutes, depending on composition and dosage and is followed by rapid loss in workability. High range super plasticizer was used in all the concrete mixes to achieve good workability. Super plasticizers are added to reduce the water requirement by 15 to $20 \%$.

\section{Experimental Results}

\section{Compressive Strength on hardened concrete}


International Journal of Science and Research (IJSR)

ISSN (Online): 2319-7064

Index Copernicus Value (2013): 6.14 | Impact Factor (2015): 6.391

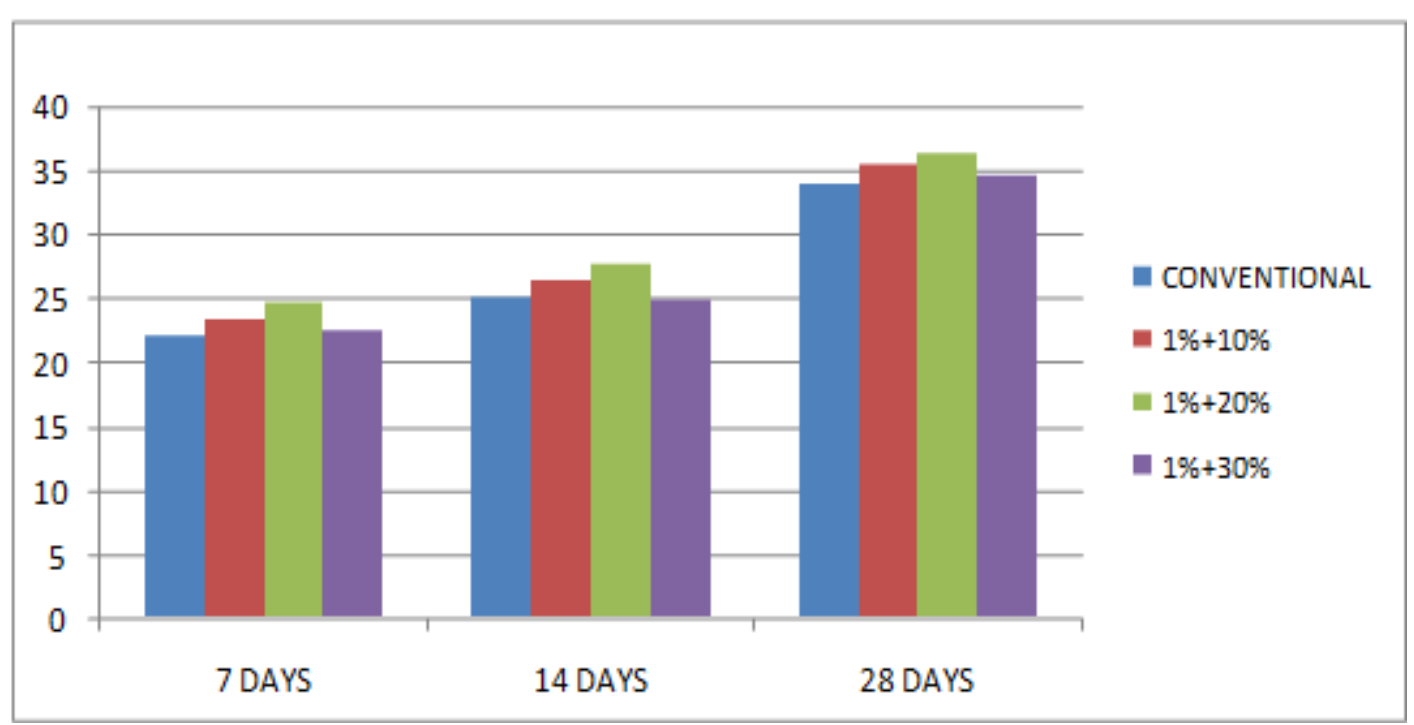

Graphical representation of M30 compressive strength

\section{Split Tensile Strength}

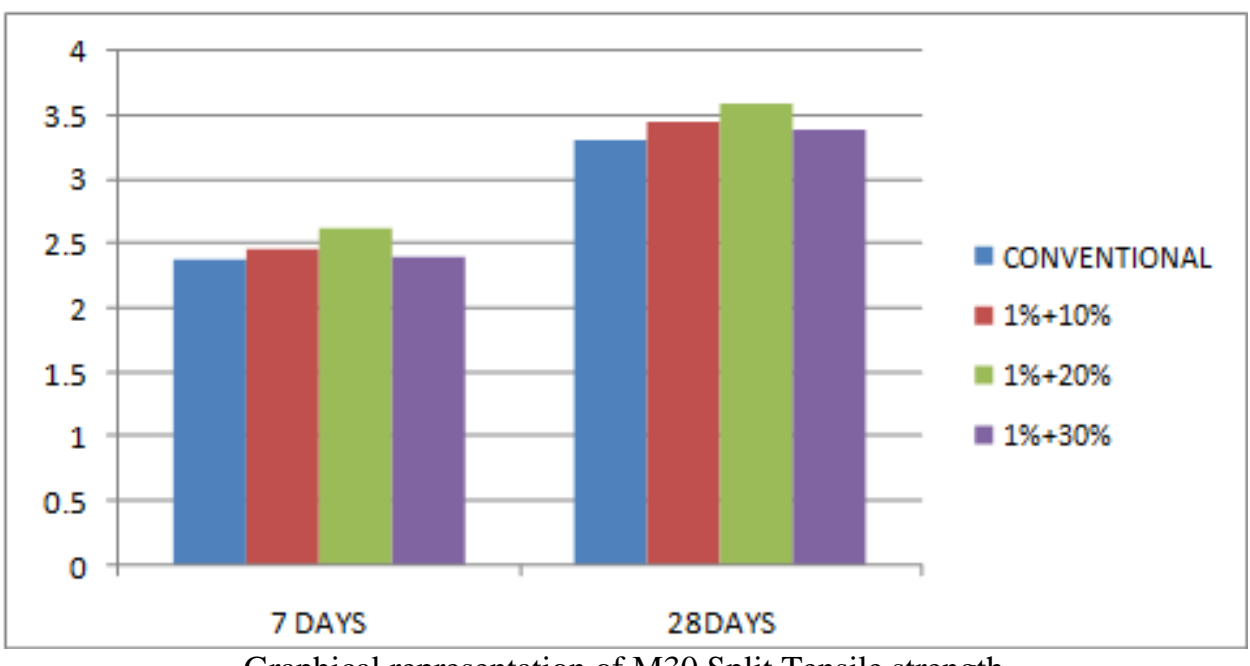

Graphical representation of M30 Split Tensile strength

\section{Flexural Strength}

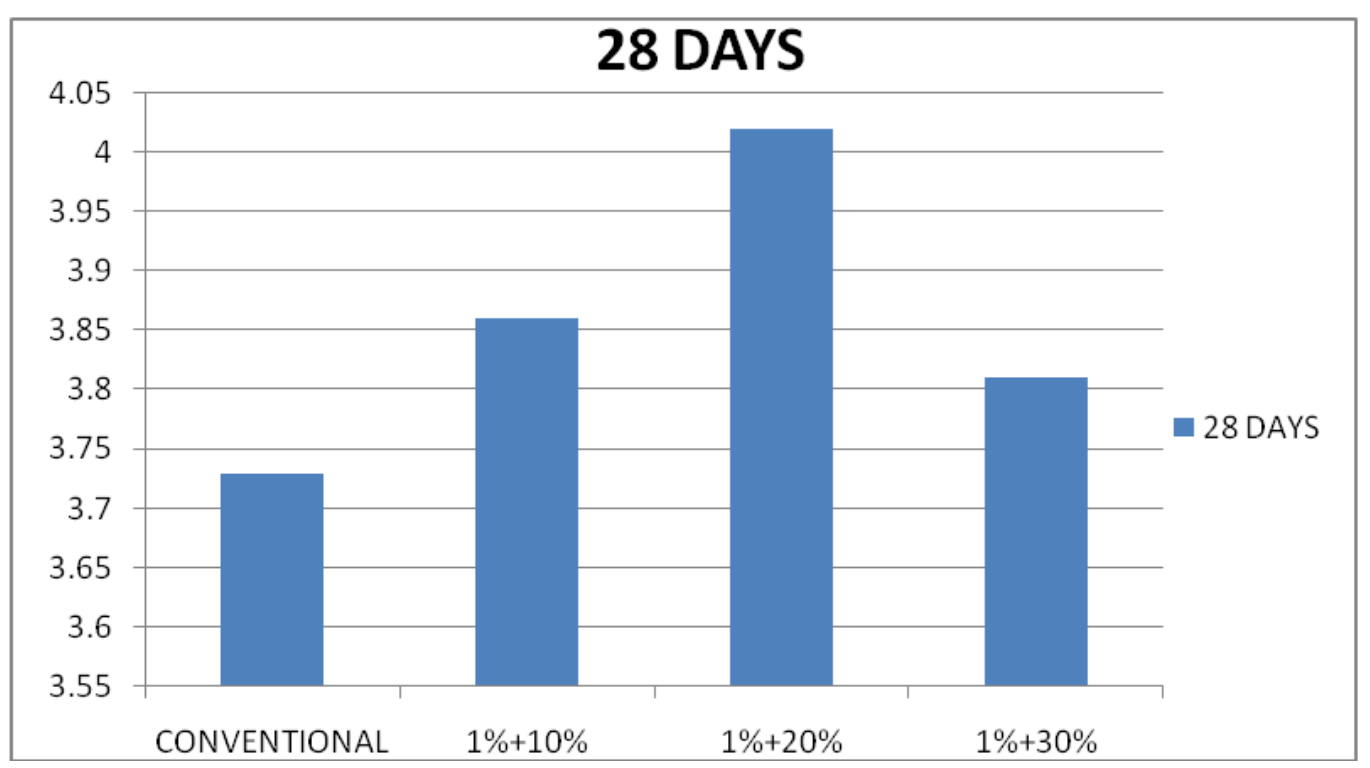

Graphical representation of M30 Flexural strength

\section{Volume 5 Issue 6, June 2016} www.ijsr.net

Licensed Under Creative Commons Attribution CC BY 


\section{Conclusion}

This study was carried to obtain the results, tests conducted on blast furnace slag powder modified cement concrete mix, in order to ascertain the influence of blast furnace slag powder and sisal fibre on the characteristic strength of concrete.

- The optimum dosage for partial replacement of cement by ground granulated blast furnace slag is $20 \%$

- The rate of gain of compressive strength of GGBS concrete is slow in the initial stag i.e. up to 14 days $\&$ as the curing period increases strength also increases

- The compressive strength, tensile strength and flexural strength of sisal \& GGBS added concrete increases with increase in GGBS content

- The compressive strength, tensile strength and flexural strength of concrete decreased at the dosage of $30 \%$ replacement of cement by GGBS

\section{References}

[1] Abdul Rahuman and SaikumarYeshika (2015), properties of sisal fibre reinforced concrete with different mix proportions and different percentage of fibre addition

[2] AtulDubey, Dr.R.Chandak (2012), Effect of blast furnace slag powder on compressive strength of concrete

[3] Dr.N.R.Krishnamurthy (2013), Addition Of The Natural Fibres Into Concrete

[4] M.Pavan Kumar (2015), The Behaviour of Concrete by Partial Replacement of Fine Aggregate with Copper Slag and Cement with GGBS

[5] Nikhil A. Gadge (2013), Mix Design of Fibre Reinforced Concrete (FRC) Using Slag \& Steel Fibre

[6] ReshmaRughooputh and JaylinaRana (2014), Partial Replacement of Cement by Ground Granulated Blast furnace Slag In Concrete

[7] S.Arivalagan (2014), Sustainable Studies on Concrete with GGBS as a Replacement Material in cement. 